\title{
Effects of light intensity on the growth, photosynthetic characteristics, and secondary metabolites of Eleutherococcus senticosus Harms
}

\author{
M.Y. XU*, K.X. WU**, Y. LIU**, J. LIU**, and Z.H. TANG ${ }^{* *++}$ \\ First Affiliated Hospital, Heilongjiang University of Chinese Medicine, 150040 Harbin, China* \\ Key Laboratory of Plant Ecology, Northeast Forestry University, 150040 Harbin, China**
}

\begin{abstract}
In this investigation, we used the growth, photosynthetic physiological parameters, and targeted metabolite analysis to evaluate the responses of Eleutherococcus senticosus in different shading treatments. The results showed that the moderate shading treatment $\left(Z_{1}\right)$ promoted the growth and inhibited photosynthesis of plants. The severe shading treatment $\left(Z_{2}\right)$ inhibited both the growth and photosynthesis of the plants. Besides, $Z_{1}$ had no significant effect on the PSII, while $Z_{2}$ inhibited the PSII. Most of the eight medicinal metabolites accumulated in the $Z_{1}$. The $\mathrm{C}_{6} \mathrm{C}_{1}-$ and $\mathrm{C}_{6} \mathrm{C}_{3}$-type phenolics accumulated in the $\mathrm{Z}_{1}$, and the $\mathrm{C}_{6} \mathrm{C}_{3} \mathrm{C}_{6}$-type in the $\mathrm{Z}_{2}$. In conclusion, the moderate shading treatment accumulated more defensive phenolics; this might be the reason for this shading condition promoting the growth and the accumulation of medicinal metabolites of the plant. The result of this study laid a theoretical foundation for the further study of shading treatments on the secondary metabolism of Eleutherococcus senticosus.
\end{abstract}

Additional key words: chlorophyll fluorescence; effective components; medicinal plant; phenols.

\section{Introduction}

Eleutherococcus senticosus (Rupr. Maxim.) Harms, family Araliaceae, is a well-known traditional Chinese herbal plant. The species is widely cultivated in eastern Asia and far western Russia (Zhou et al. 2018a). In recent years, E. senticosus have become popular in the United States and European countries as a new medicinal plant and dietary supplement. The plant has many pharmacological effects, including antibacterial, anticancer, anti-inflammatory, antigout, anti-hepatitis, antioxidant, antipyretic effects; other effects include choleretic, hemostasis, immune stimulation, cholesterol-lowering, and radiation protection (Yi et al. 2001, Yoon et al. 2004, Park et al. 2006, Zhou et al. 2018b, Wang et al. 2019). E. senticosus contains a variety of pharmaceutical compounds, including lignin, coumarins, triterpenoid saponins, flavonoids, vitamins, minerals, and polysaccharides. Because of the lack of standardization for cultivation, some E. senticosus appeared in a poor quality at China market. It has been confirmed that $26 \%$ of the products did not meet the content of the compounds described on the label (Arouca and Grassi-Kassisse 2013). So, studying the appropriate cultivation conditions of
E. senticosus has an essential significance for controlling the quality of this medicinal plant.

Light not only provides a source of energy but also acts as a signal for environmental changes to induce various physiological responses in plants (Abidi et al. 2013). During the growth of medicinal plants, appropriate light intensity could help plants defend against the inhibition of photosynthesis and abiotic stress. In addition, the material and density of the shading material also affect the quality of medicinal plants (Feijó et al. 2009, Kim et al. 2016, Oliveira et al. 2016). The effects of environmental stress on photosynthesis of medicinal plants include regulating the stomatal size and causing damage to the PSII reaction center (Berry and Downton 1982). Previous studies showed that the effects of shading conditions on photosynthesis of different medicinal plants were different (Wang et al. 2017, Tafoya et al. 2018, Fan et al. 2019).

Shading also changed the synthesis of secondary metabolites in plants. Previous studies showed that the light intensity affected the accumulation of flavonoids, phenolics, alkaloids, and lignin in medicinal plants (Poolman et al. 2013, Kong et al. 2016, Pan and Guo 2016, Arena et al. 2017, Lazzarini et al. 2018). Light intensity affects

Received 9 March 2020, accepted 27 May 2020.

${ }^{+}$Corresponding author; phone: +86-451-8219-2098, e-mail: tangzh@nefu.edu.cn

Abbreviations: $C_{\mathrm{i}}$ - intercellular $\mathrm{CO}_{2}$ concentration; $E$ - transpiration rate; $\mathrm{F}_{0}-$ minimal fluorescence yield of the dark-adapted state; $\mathrm{F}_{\mathrm{m}}$ - maximal fluorescence yield of the dark-adapted state; $\mathrm{F}_{\mathrm{v}} / \mathrm{F}_{\mathrm{m}}$ - maximal quantum yield of PSII photochemistry; GK - control group; $g_{\mathrm{s}}-$ stomatal conductance; $P_{\mathrm{N}}-$ net photosynthetic rate; $\mathrm{Q}$ - principal component analysis score; WUE - water-use efficiency $\left(=P_{\mathrm{N}} / E\right)$; $\mathrm{Z}_{1}$ - moderate shading treatment; $\mathrm{Z}_{2}$ - severe shading treatment.

Acknowledgments: This research was funded by the Central Financial Forestry Science and Technology Promotion Project (grant number 2019-12); the Special Fund for Forest Scientific Research in the Public Welfare (grant number 201504701-2); key project of Heilongiiang Provincial Administration of Traditional Chinese Medicine (grant number 2018-009). We thank the anonymous reviewers for improving the quality of the manuscript. 
synthesis of the secondary metabolites in the medicinal plant by regulation of secondary metabolic pathways. Some studies reported that light intensity regulated the metabolism of flavonoids and phenylpropanoids in medicinal plants (Horváth and Szász 1965, Kitazaki et al. 2018). Phenolics are common secondary metabolites in plants. They have anti-infective and antioxidative effects (Lee and Chiu 2015, Kasprzak et al. 2018), and also have plant protective properties (Warren et al. 2015). Phenolics exist in plants in three skeletal types, including metabolites with $\mathrm{C}_{6}-\mathrm{C}_{1}, \mathrm{C}_{6}-\mathrm{C}_{3}$, and $\mathrm{C}_{6}-\mathrm{C}_{3}-\mathrm{C}_{6}$ types. The three types of phenolics are the defensive metabolites through the antibacterial effects (Tugizimana et al. 2019). UPLCMS and GC-MS techniques were also applied to study mechanisms of environmental stress in plant secondary metabolism regulation (Tang et al. 2017, Yang et al. 2017).

As far as we know, there is no comprehensive study on the growth, photosynthetic characteristics, medicinal compounds, and phenolics of E. senticosus under the shading treatment. The artificial cultivation area of the plant increases in China. Understanding how environmental factors affect the growth and photosynthesis and the accumulation of secondary metabolites in E. senticosus can be used for the standardized cultivation. We hypothesized that the light intensity effected the growth, photosynthesis, and accumulation of the secondary metabolites of $E$. senticosus. Three shading treatment groups were set up for the purpose and to find the most suitable light intensity conditions. The result can provide the basis for further study on the secondary metabolism of E. senticosus under different light intensity.

\section{Materials and methods}

Chemicals and reagents: Syringin, eleutheroside E, isofraxidin, hyperoside, rutin, kaempferol, oleanolic acid, and L-phenylalanine were purchased from the Chinese National Institute of Control of Pharmaceutical and Biological Products (Beijing, China). Syringic acid, vanillic acid, $p$-hydroxybenzoic, protocatechuic acid, cinnamic acid, gallic acid, ferulic acid, chlorogenic acid, caffeic acid, p-coumaric acid, luteolin, genistein, and quercetin were purchased from ChromaDex Inc. (Santa Ana, CA, USA). The water used for UPLC-MS/MS was prepared by a Milli- $Q$ (Millipore, Bedford, MA, USA). Acetonitrile ( $J \& K$ Scientific Ltd., Beijing, China) was HPLC grade. All other chemicals used in the research were of analytical grade.

Plant materials: The three-year-old E. senticosus were obtained from Qitaihe, Heilongjiang Province, China $\left(45^{\circ} 95^{\prime} \mathrm{N}, 131^{\circ} 05^{\prime} \mathrm{E}\right)$, and planted in the Botanical Garden of the Heilongjiang University of Chinese Medicine, Harbin, Heilongjiang Province, China $\left(45^{\circ} 72^{\prime} \mathrm{N}, 126^{\circ} 64^{\prime} \mathrm{E}\right)$ in April. A month after, seedlings were transplanted in pots of 30-cm diameter (May) containing potting soil (mixed with peat, perlite, and vermiculite):sand $(1: 1, \mathrm{v} / \mathrm{v})$, and the $\mathrm{pH}$ of the soil was 6.5 . The maximum water holding capacity of the soil is $50 \%$.
Light intensity treatment: We started the shading treatment on 15 June 2017. The shade shed was placed in the greenhouse (covered with one-layer opaque plastic film) and built with black mesh cloth. Each shed was $3 \mathrm{~m}$ long, $1.5 \mathrm{~m}$ wide, and $1.4 \mathrm{~m}$ high. Then, three shading treatments were set according to the bionic light conditions for wild E. senticosus: control group (forest edge, 100\%, GK) no shade; moderate shading group (forest gap, $38.8 \%$, $Z_{1}$ ) - one-layer thick mesh cloth; severe shading group (understory, $16.9 \%, Z_{2}$ ) - two layers of thick mesh cloth. The light intensities on sunny days were measured at noon by using a PAR sensor (6400XT portable photosynthesis system, LI-COR Biosciences, Lincoln, NE) in July and August for the shading treatments, and PPFD were calculated (Table 1S, supplement). After the treatment start, the soil $\mathrm{pH}$ was maintained at 6.5 , and the soil water content was maintained at about $60-75 \%$ of the maximum water-holding capacity. Throughout the experiment, tap water was used as the source of irrigation water, and its $\mathrm{pH}$ was 8 , and the temperature in the greenhouse was controlled at $23-25^{\circ} \mathrm{C}$. The experiment was conducted throughout all the plant developmental stage process (from June to August), and each treatment was performed in three replications. Six plants per replications were investigated, and each plant was used for sample collections and analysis. The whole plant was separated into roots, stems, and leaves for metabolic analysis.

Growth parameters: A sampling of plant material was done after two months of shading treatment. Six plants were randomly selected in each treatment group. Measurements of plant height, main stem diameter, crown width, root length, total leaf area, and plant leaf number were performed. The total leaf area was measured with $L I-3100$ leaf area meter (LI-COR Biosciences, Lincoln, Nebraska, USA). Each sample was measured three times in parallel.

Photosynthetic characteristics: Gas-exchange parameters were measured in a glasshouse from 10:00-13:00 h on 30 July 2017 . Weather conditions were normal during the investigation. The net photosynthetic rate $\left(P_{\mathrm{N}}\right)$, stomatal conductance $\left(g_{\mathrm{s}}\right)$, transpiration rate $(E)$, and intercellular $\mathrm{CO}_{2}$ concentration $\left(C_{\mathrm{i}}\right)$ values were provided by the photosynthesis measuring system ( $L i-6400 X T, L I-C O R$, USA). Water-use efficiency (WUE) was calculated as $P_{\mathrm{N}} / E$. Chlorophyll (Chl) fluorescence parameters, including the minimum fluorescence $\left(\mathrm{F}_{0}\right)$, maximum fluorescence $\left(\mathrm{F}_{\mathrm{m}}\right)$, potential photochemical efficiency $\left(\mathrm{F}_{\mathrm{v}} / \mathrm{F}_{0}\right)$, maximum photochemical efficiency $\left(\mathrm{F}_{\mathrm{v}} / \mathrm{F}_{\mathrm{m}}\right)$ values were provided by the Chl fluorescence system (PAM-2500, Walz, Effeltrich, Germany). Before the Chl fluorescence parameters were measured, the leaves were dark-adapted for $30 \mathrm{~min}$. Six plants were randomly selected in each treatment group.

The LC-MS analysis of active medicinal ingredients: The samples were ground with a grinder and passed through a 35-mesh sieve. Dry powder samples of $2 \mathrm{~g}$ were dissolved in $10 \mathrm{ml}$ of methanol $(80 \%)$ for 45 -min ultrasonic extraction and filtered repeatedly. After centrifugation at 
$532.88 \mathrm{~Pa}$ for $10 \mathrm{~min}$, the supernatant was evaporated to dryness under vacuum. The amount of the solution precipitated with methanol was then $1.0 \mathrm{ml}$. All samples were filtered through a $0.22-\mu \mathrm{m}$ diameter microporous filter membrane and injected into the mass spectrometry instrument. Each sample was measured in parallel three times.

The quantitative conditions of determination of eight active compounds were the same as in our previous studies (Xu et al. 2019). The UPLC-MS analysis was performed with an ACQUITY UPLC system (Waters Corporation, Japan) coupled with an $L C$-20AD pump, SIL-20A autosampler (Waters Corporation, Japan). The ACQUITY UPLC BEH C18 column $(1.7 \mu \mathrm{m}, 2.1 \times 50 \mathrm{~mm})$ used for UPLC was held at $25^{\circ} \mathrm{C}$; injection volume was $10.0 \mu \mathrm{L}$; the flow rate was $0.5 \mathrm{~mL} \mathrm{~min}{ }^{-1}$. Mobile phase A consisted of methanol, while the mobile phase B comprised water. The chromatographic column was eluted with a linear gradient of $25 \%$ A for $0-1.5 \mathrm{~min}, 25-50 \%$ A for $1.5-2.0 \mathrm{~min}$, $50 \%$ A for $2.0-4.0 \mathrm{~min}, 50-90 \%$ A for $4.0-4.5 \mathrm{~min}, 90 \% \mathrm{~A}$ for $4.0-4.5 \mathrm{~min}, 90-25 \% \mathrm{~A}$ for $5.5-6.0 \mathrm{~min}$, and $25 \% \mathrm{~A}$ for 6.0-7.0 min. Mass spectrometric detection was performed using QTRAP 5500 (AB SCIEX, USA) equipped with electrospray ionization (ESI) source. Operation parameters were: cone voltage of $3 \mathrm{kV}$ and ion source atomizing gas temperature of $500^{\circ} \mathrm{C} ; 25$ psi atomizing gas and $20 \mathrm{psi}$ air curtain gas. The ion pair, cluster voltage, collision voltage, and collision chamber injection voltage of eight active compounds are shown in Table 2S (supplement). Both MS and MS/MS data were determined in the positive mode, and data were used for multiple reaction monitoring (Fig. 1S, supplement).

The targeted metabolic analytical conditions for 13 phenolic metabolites were the same as in our previous studies (Xu et al. 2020). Samples were analyzed using an LC system coupled to a QTOF tandem-mass spectrometer via electrospray ionization (ESI) interface (Agilent 6520, Agilent Technologies, Santa Clara, CA, USA). Sample extracts were separated through a reversed-phase on a Shimpack LC column (VP-ODS C18, pore size $5.0 \mu \mathrm{m}$, $2 \times 150 \mathrm{~mm}$ ). The mobile phase comprised of solvent A and solvent B. Solvent A contained $0.04 \%$ acetic acid in the water, and solvent B contained $0.04 \%$ acetic acid in acetonitrile. The following gradient was adapted a flow rate of $0.5 \mathrm{~mL} \mathrm{~min}^{-1}$ : 0-20 min of 5-95\% $\mathrm{B} ; 20-22.1 \mathrm{~min}$ of $95-5 \% \mathrm{~B} ; 22.1-28 \mathrm{~min}$ of $5-5 \% \mathrm{~B}$. Blank measurement with the initial solvent was made after each HPLC run. The injection volume and column temperature were adjusted to $5 \mu \mathrm{L}$ and $40^{\circ} \mathrm{C}$. Optimal MS conditions for positive ion electrospray were: capillary temperature of $350^{\circ} \mathrm{C}$; curtain gas pressure of $40 \mathrm{psi}$; capillary voltage of $3,500 \mathrm{~V}$; fragmentation voltage of $135 \mathrm{~V}$. The instrument was tuned prior to each batch run. A full-scan is ranging between $50-1000 \mathrm{~m} / \mathrm{z}$ and was conducted with a scan time of $1 \mathrm{~s}$ and an interscan delay of $0.1 \mathrm{~s}$ in centered mode.

Statistical analysis: All results were executed to the study of variance (ANOVA) to determine the significant differences between shading treatments. If one-way ANOVA was performed, Duncan's honestly significant difference (HSD) post hoc tests were conducted to determine the differences between individual treatments (SPSS 22.0, SPSS Inc., USA). All bar graphs are plotted using GraphPad 6.0 (GraphPad Software Inc., USA). Heat maps of phenol metabolites were drawn using the ' $R$ ' software (https://www.r-project.org/).

\section{Results}

Growth parameters: Shading conditions affected the growth of E. senticosus (Table 1). The plant height, stem diameter, crown width, root length, leaf number, and leaf area in the $Z_{1}$, respectively, increased by $33.8,43.3,43.2$, $55.7,24.6$, and $34.2 \%$ compared with the GK. The plant height, stem diameter, crown width, root length, and leaf area in the $Z_{2}$, respectively, decreased by $13.4,22.9,20.7$, 18.4 , and $17.4 \%$ compared within the GK, the leaf number increased by $51.8 \%$. The results showed that the $Z_{1}$ was more favorable for the growth of E. senticosus, while $\mathrm{Z}_{2}$ inhibited the growth of the plants.

Photosynthetic parameters: Shading also affected the gas-exchange parameters of E. senticosus (Table 2). The $P_{\mathrm{N}}$ in the $\mathrm{Z}_{1}$ and $\mathrm{Z}_{2}$ was 72.3 and $58.4 \%$, respectively, of that in the GK. The $g_{\mathrm{s}}$ in the $Z_{1}$ and $Z_{2}$ was 58.3 and $36.5 \%$ of that in the GK. The $C_{\mathrm{i}}$ in $\mathrm{Z}_{1}$ and $\mathrm{Z}_{2}$ was 105.5 and $121.3 \%$, respectively, of that in the GK. The $E$ in the $Z_{1}$ and $Z_{2}$ was 88.2 and $82.9 \%$, respectively, of that in the GK. Shading also affected the $\mathrm{Chl}$ fluorescence parameters of E. senticosus (Fig. 1). The $\mathrm{F}_{0}$ in the $\mathrm{Z}_{1}$ increased with the shading treatment days (Fig. 1A). After $90 \mathrm{~d}$ of shading treatment, there was no significant difference between the $Z_{1}$ and the GK. The $F_{0}$ in $Z_{2}$ was significantly higher than that of the GK. The $F_{m}$ increased with shading treatment days in the $Z_{1}$ and was higher than that in the GK on the $90^{\text {th }}$ day (Fig. $1 B$ ). The $\mathrm{F}_{\mathrm{m}}$ in the $\mathrm{Z}_{2}$ decreased

Table 1. Effect of light intensity on growth parameters of Eleutherococcus senticosus. Means $( \pm \mathrm{SD}, n=6)$ followed by a different small letter in the same column are significantly different $(p<0.05)$. GK - control group; $Z_{1}$ - moderate shading group; $Z_{2}-$ severe shading group.

\begin{tabular}{lllllll}
\hline $\begin{array}{l}\text { Treatment } \\
\text { group }\end{array}$ & $\begin{array}{l}\text { Plant height } \\
{[\mathrm{cm}]}\end{array}$ & $\begin{array}{l}\text { Stem diameter } \\
{[\mathrm{mm}]}\end{array}$ & $\begin{array}{l}\text { Crown width } \\
{[\mathrm{cm}]}\end{array}$ & $\begin{array}{l}\text { Root length } \\
{[\mathrm{cm}]}\end{array}$ & $\begin{array}{l}\text { Leaf number } \\
{\left[\begin{array}{l}\text { L }] \\
{\left[\mathrm{mm}^{2}\right]}\end{array}\right.}\end{array}$ \\
\hline $\mathrm{GK}$ & $11.612 \pm 0.274^{\mathrm{a}}$ & $10.960 \pm 0.358^{\mathrm{a}}$ & $32.602 \pm 0.456^{\mathrm{a}}$ & $11.588 \pm 0.215^{\mathrm{a}}$ & $19.000 \pm 0.495^{\mathrm{a}}$ & $14.336 \pm 0.378^{\mathrm{a}}$ \\
$\mathrm{Z}_{1}$ & $15.540 \pm 0.351^{\mathrm{b}}$ & $15.707 \pm 0.149^{\mathrm{b}}$ & $46.695 \pm 0.476^{\mathrm{b}}$ & $18.038 \pm 0.385^{\mathrm{b}}$ & $23.667 \pm 0.316^{\mathrm{b}}$ & $19.238 \pm 0.503^{\mathrm{b}}$ \\
$\mathrm{Z}_{2}$ & $10.055 \pm 0.262^{\mathrm{c}}$ & $8.455 \pm 0.202^{\mathrm{c}}$ & $25.863 \pm 0314^{\mathrm{c}}$ & $9.462 \pm 0.260^{\mathrm{c}}$ & $28.833 \pm 0.501^{\mathrm{c}}$ & $11.836 \pm 0.241^{\mathrm{c}}$ \\
\hline
\end{tabular}


Table 2. Effect of light intensity on the photosynthetic parameters of Eleutherococcus senticosus. Means $( \pm \mathrm{SD}, n=6)$ followed by a different small letter in the same column are significantly different $(p<0.05)$. GK - control group; $\mathrm{Z}_{1}-$ moderate shading group; $\mathrm{Z}_{2}$ - severe shading group.

\begin{tabular}{llllll}
\hline $\begin{array}{l}\text { Treatment } \\
\text { group }\end{array}$ & $\begin{array}{l}P_{\mathrm{N}} \\
{\left[\mu \mathrm{mol} \cdot \mathrm{m}^{-2} \mathrm{~s}^{-1}\right]}\end{array}$ & $\begin{array}{l}g_{\mathrm{s}} \\
{\left[\mathrm{mol}\left(\mathrm{H}_{2} \mathrm{O}\right) \mathrm{m}^{-2} \mathrm{~s}^{-1}\right]}\end{array}$ & $\begin{array}{l}C_{\mathrm{i}} \\
{\left[\mu \mathrm{mol}\left(\mathrm{CO}_{2}\right) \mathrm{mol}^{-1}\right]}\end{array}$ & $\begin{array}{l}E \\
{\left[\mathrm{mmol}\left(\mathrm{H}_{2} \mathrm{O}\right) \mathrm{m}^{-2} \mathrm{~s}^{-1}\right]}\end{array}$ & $\begin{array}{l}\text { WUE } \\
{\left[\mathrm{mol}\left(\mathrm{CO}_{2}\right) \mathrm{mol}\left(\mathrm{H}_{2} \mathrm{O}\right)^{-1}\right]}\end{array}$ \\
\hline $\mathrm{GK}$ & $7.566 \pm 0.218^{\mathrm{a}}$ & $0.096 \pm 0.003^{\mathrm{a}}$ & $235.481 \pm 6.381^{\mathrm{a}}$ & $1.532 \pm 0.039^{\mathrm{a}}$ & $4.939 \pm 0.158^{\mathrm{a}}$ \\
$\mathrm{Z}_{1}$ & $5.469 \pm 0.271^{\mathrm{b}}$ & $0.056 \pm 0.003^{\mathrm{b}}$ & $248.306 \pm 7.149^{\mathrm{b}}$ & $1.351 \pm 0.040^{\mathrm{b}}$ & $4.048 \pm 0.112^{\mathrm{b}}$ \\
$\mathrm{Z}_{2}$ & $4.417 \pm 0.214^{\mathrm{c}}$ & $0.035 \pm 0.002^{\mathrm{c}}$ & $285.079 \pm 5.625^{\mathrm{c}}$ & $1.270 \pm 0.036^{\mathrm{c}}$ & $3.005 \pm 0.085^{\mathrm{c}}$ \\
\hline
\end{tabular}

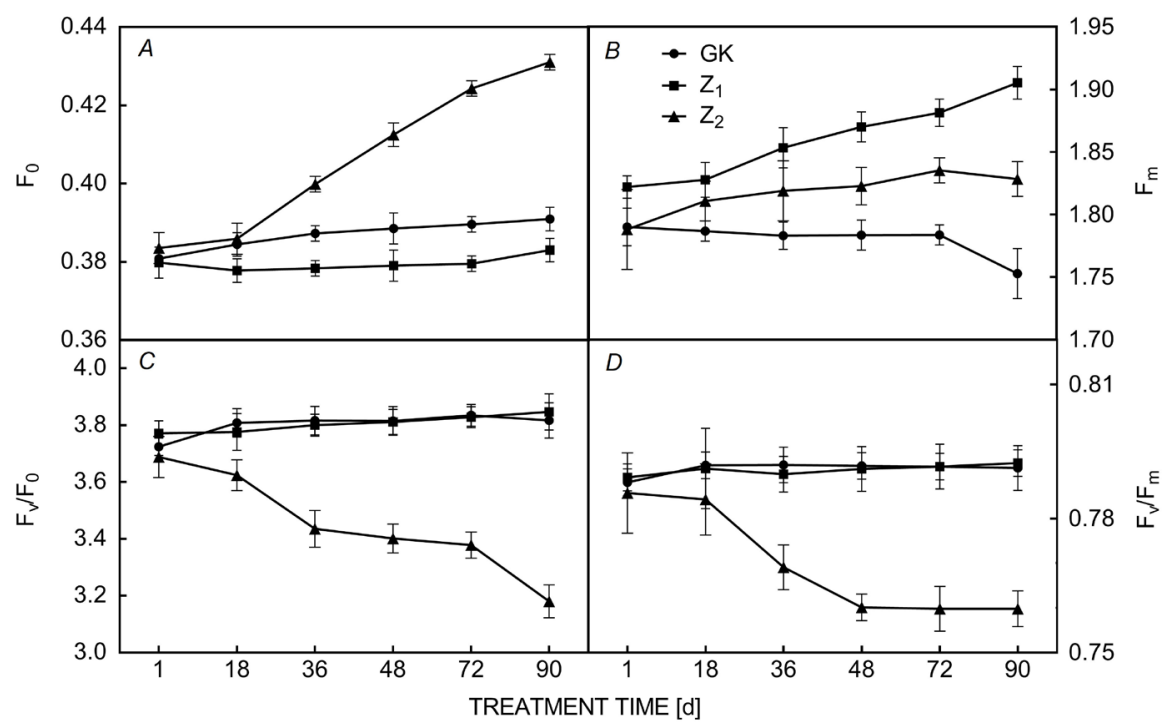

Fig. 1. Effects of different shading conditions on Chl fluorescence parameters of Eleutherococcus senticosus (means $\pm \mathrm{SD}, n=6)$. $\mathrm{F}_{0}$, minimum fluorescence $(A) ; \mathrm{F}_{\mathrm{m}}$, maximum fluorescence $(B) ; \quad \mathrm{F}_{\mathrm{v}} / \mathrm{F}_{0}$, latent photochemical efficiency $(C) ; \quad \mathrm{F}_{\mathrm{v}} / \mathrm{F}_{\mathrm{m}}$, maximum photochemical efficiency (D). GK - control group (•); $\mathrm{Z}_{1}-$ moderate shading group ( $\mathbf{\square}) ; Z_{2}-$ severe shading group $(\boldsymbol{\Lambda})$.

on the $20^{\text {th }}$ day and was lower than that in the GK on the $90^{\text {th }}$ day. The $\mathrm{F}_{\mathrm{v}} / \mathrm{F}_{0}$ in the $\mathrm{Z}_{2}$ was lower than that in the $\mathrm{GK}$, while that in the $Z_{1}$ was not distinct from the GK (Fig. 1C). There was no difference of $\mathrm{F}_{\mathrm{v}} / \mathrm{F}_{\mathrm{m}}$ between the $Z_{1}$ and the $G K$, while the $Z_{2}$ decreased with the shading treatment days, and was lower than that in the GK and the $\mathrm{Z}_{1}$ on the $90^{\text {th }}$ day $($ Fig. $1 D$ ).

Medicinal compounds: The Q value of principal component analysis was used to illustrate the overall trend in contents of the compounds studied in roots, stems, and leaves under different shading conditions (Fig. 2). The compounds studied showed the same accumulation trend in various organs. The content of the medicinal compounds was the highest in the $Z_{1}$.

In the roots, the contents of oleanolic acid, rutin, kaempferol, hyperoside, eleutheroside $\mathrm{E}$, isofraxidin, and syringin in the $Z_{1}$, respectively, increased by $44.9,150.0$, $100.0,60.0,101.2,97.8$, and $85.2 \%$ compared with the GK, while the contents of L-phenylalanine in the $Z_{1}$ decreased by $5.4 \%$ compared with the GK. The contents of rutin, kaempferol, hyperoside, and eleutheroside $\mathrm{E}$ in the $Z_{2}$, respectively, increased by $83.3,157.1,73.3$, and $40.4 \%$ compared with the GK. The contents of L-phenylalanine, oleanolic acid, isofraxidin, and syringin in the $Z_{2}$, respectively, decreased by $37.8,19.2,26.9$, and $40.0 \%$ compared with the GK (Fig. 3).

In the stems, the contents of rutin, kaempferol, hypero- side, eleutheroside E, isofraxidin, and syringin in the $\mathrm{Z}_{1}$, respectively, increased by $53.3,33.3,42.5,64.8$, 54.9 , and $41.5 \%$ compared with the GK. The contents of L-phenylalanine, and oleanolic acid in the stems in the $\mathrm{Z}_{1}$, respectively, decreased by 40.0 and $73.3 \%$ compared with the GK. The contents of rutin, kaempferol, and hyperoside in the stems in the $Z_{2}$, respectively, increased by 86.7 , 93.3, and $66.7 \%$ compared with the GK. The contents of L-phenylalanine, oleanolic acid, eleutheroside E, isofraxidin, and syringin in the $Z_{2}$, respectively, decreased by $21.0,37.5,19.1,67.3$, and $48.3 \%$ compared with the GK (Fig. 3).

In the leaves, the contents of L-phenylalanine, oleanolic acid, rutin, hyperoside, kaempferol, eleutheroside E, isofraxidin, and syringin in the $Z_{1}$, respectively, increased by $147.7,100.4,147.5,68.0,43.9,14.7,800.0$, and $17.4 \%$ compared with in the GK. The contents of L-phenylalanine, oleanolic acid, eleutheroside $\mathrm{E}$, isofraxidin, and syringin in the $Z_{2}$, respectively, increased by $75.9,309.3,78.0 ; 2,600$; and $78.3 \%$ compared with in the GK. The contents of rutin, hyperoside, and kaempferol, in the $Z_{2}$, respectively, decreased by $68.5,23.2$, and $51.0 \%$, compared with in the GK (Fig. 3).

Phenolic metabolites: Thirteen phenolic compounds were analyzed in the roots of E. senticosus. The phenolics can be divided into two categories according to the cumulative 
difference under different shading conditions (Fig. 4A): in $\mathrm{Z}_{1}$ - cinnamic acid, ferulic acid, $\mathrm{p}$-coumaric acid, caffeic acid, chlorogenic acid, protocatechuic acid, gallic acid, vanillic acid, p-hydroxybenzoic acid, and syringic acid; in $\mathrm{Z}_{2}$ - genistein, luteolin, and quercetin. The phenolics can be divided into three categories according to the cumulative difference in the stems under different shading conditions (Fig. 4B). The GK group contained protocatechuic acid, gallic acid, vanillic acid, and syringic acid; $Z_{1}$ group contained caffeic acid, p-coumaric acid, chlorogenic acid, cinnamic acid, and ferulic acid. $Z_{2}$ group contained

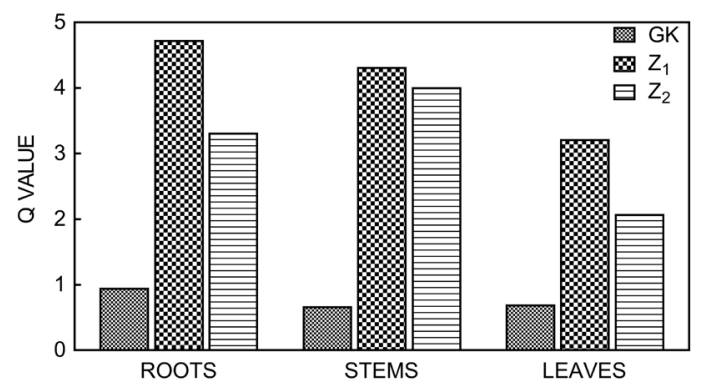

Fig. 2. The overall effects of different shading conditions on the accumulation of secondary metabolites in Eleutherococcus senticosus $(n=6)$. GK - control group; $Z_{1}$ - moderate shading group; $Z_{2}$ - severe shading group; $Q$ value - principal component analysis score. p-hydroxybenzoic acid, genistein, luteolin, and quercetin. Twelve phenolics were detected in the leaves (Fig. 4C). The phenolics can be classified into three categories according to the cumulative differences under different shading conditions. GK contained p-coumaric acid, caffeic acid, chlorogenic acid, and cinnamic acid; $\mathrm{Z}_{1}$ contained p-hydroxybenzoic acid, protocatechuic acid, vanillic acid, and gallic acid; $Z_{2}$ contained quercetin, genistein, and luteolin.

\section{Discussion}

The growth of plants is closely related to their living environment (Hammerschmidt 2004). Light intensities affected plant growth, photosynthesis, and the accumulation of secondary metabolites (Feijó et al. 2009, Kong et al. 2016, Pan and Guo 2016). Different species have different morphological responses to light intensity (Aleric and Kirkman 2005, Zhu et al. 2018, Khan et al. 2020). The results of this study showed that the plant height, stem diameter, crown width, root length, and leaf area of E. senticosus were higher in $Z_{1}$ and lower in $Z_{2}$. This is similar to the previous research (Feijó et al. 2009). Interestingly, we found that the leaf number increased with decreased light intensity, which may be the morphological change because E. senticosus adapted to the shading environment (Kim et al. 2019, Zhou et al. 2019). The reason why $\mathrm{Z}_{1}$ promoted the growth of E. senticosus might

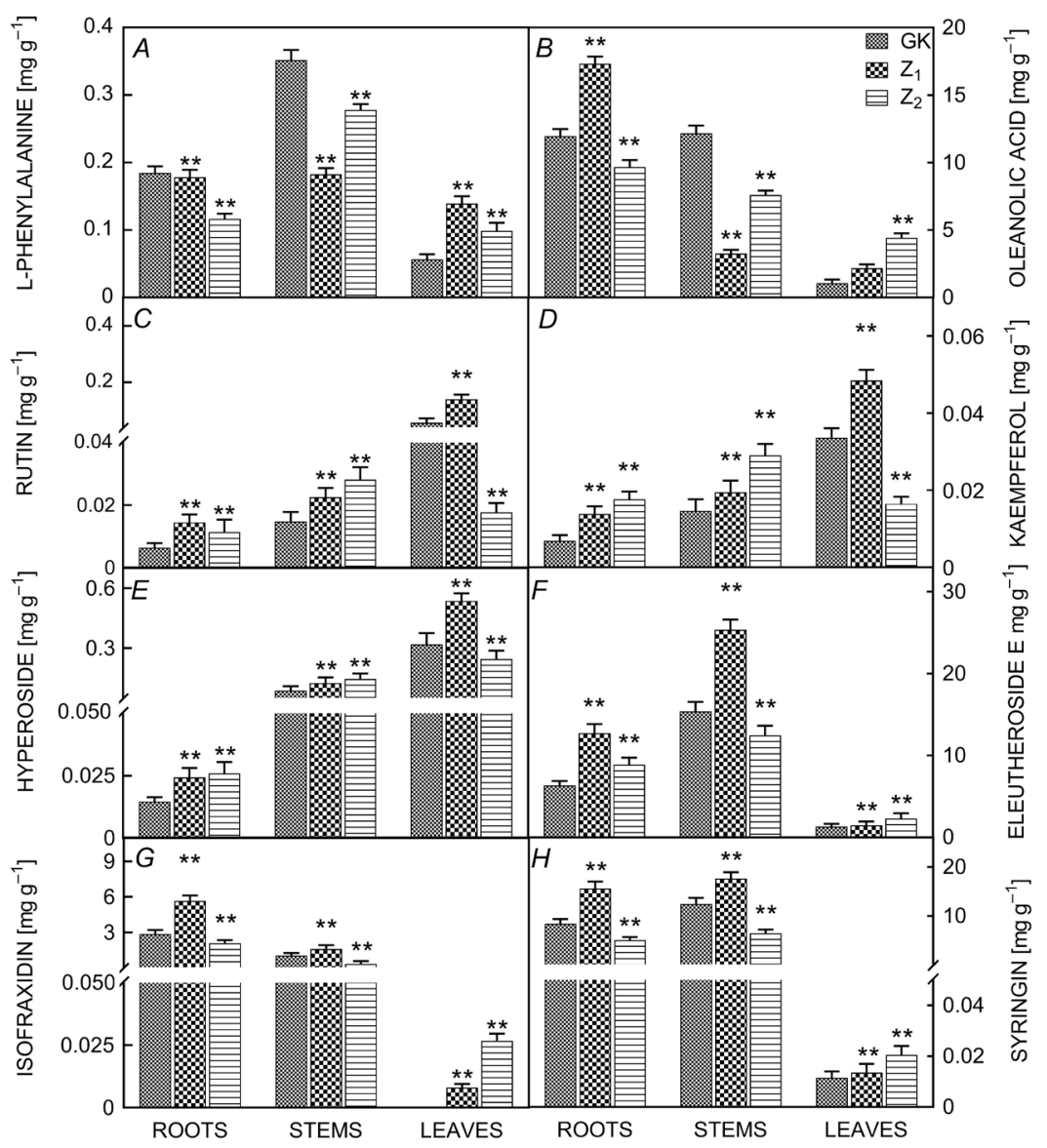

Fig. 3. The accumulation of eight secondary metabolites in different shading conditions in Eleutherococcus senticosus. GK - control group; $Z_{1}-$ moderate shading group; $Z_{2}-$ severe shading group. The bar represents the standard deviation $(n=6) .^{* *}$ indicates significant difference between the treatment group and the control group in the same medicinal part $(p<0.01)$. 

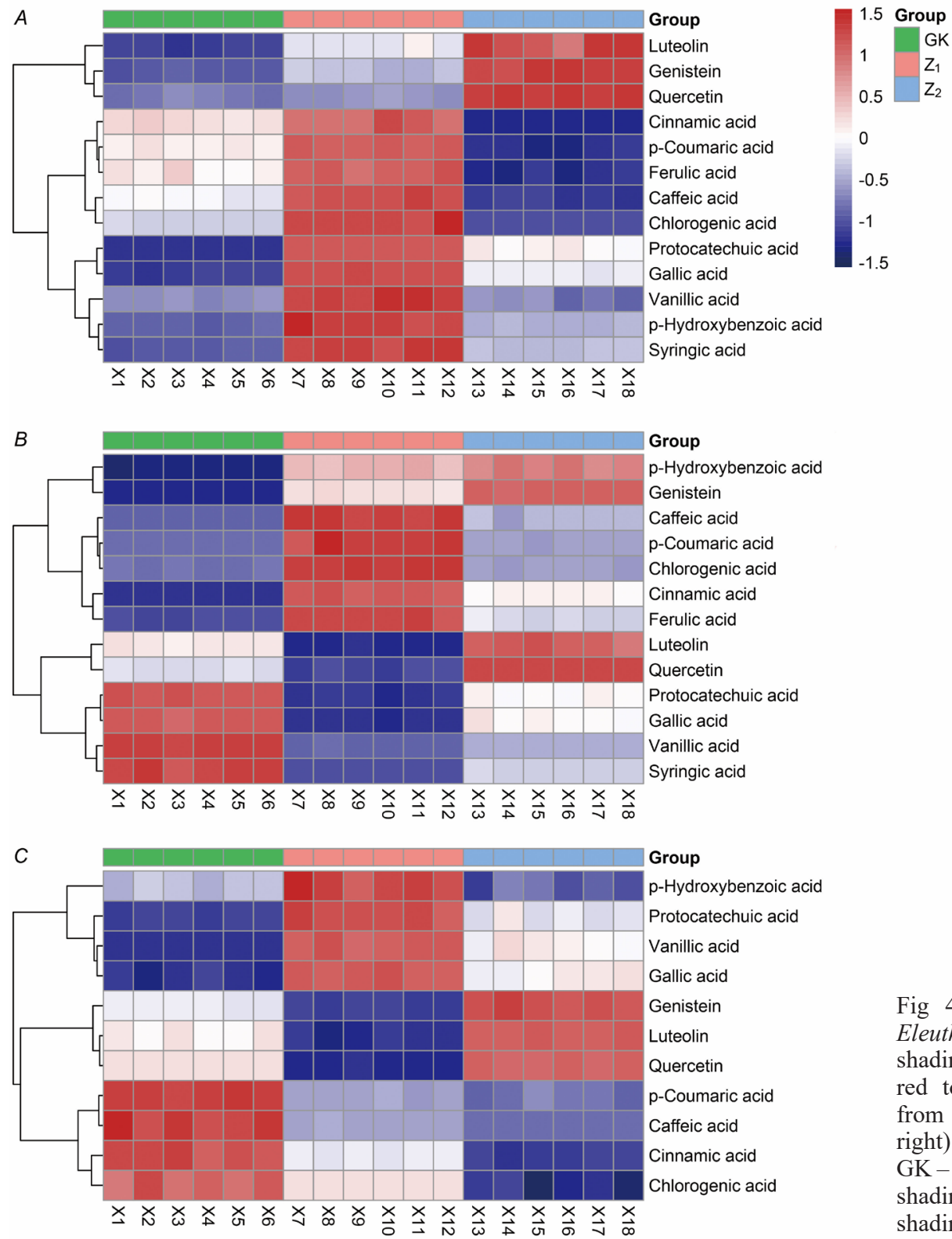

Fig 4. Cluster analysis of phenolics in Eleutherococcus senticosus under different shading conditions. The color range from red to blue indicates relative abundance from high to low (color key scale on the right). Roots $(A)$; stems $(B)$; leaves $(C)$. $\mathrm{GK}$ - control group (X1-X6); $\mathrm{Z}_{1}$ - moderate shading group $(\mathrm{X} 7-\mathrm{X} 12) ; \mathrm{Z}_{2}-$ severe shading group (X13-X18).

be that shade could help plants maintain soil moisture, improve the air humidity around plants, and help plants resist possible water stress, especially in the semiarid area (Yang et al. 2019). In this study, we found that shading environment inhibited leaf photosynthesis parameters. Therefore, we believe that the change in photosynthetic parameters is not the reason why $Z_{1}$ promoted the growth of $E$. senticosus. However, we believe that the reason for $\mathrm{Z}_{2}$ inhibiting the plant growth is low light density inhibiting the photosynthesis of E. senticosus.

The photosynthetic responses are the indicators of the plant ability to survive and grow in different environments (Gao et al. 2019). The effect of the environment on plant photosynthesis is mainly in two aspects, stomatal factors and nonstomatal factors (Jones 1985). The stomatal factors mean that the stomata control the supply of $\mathrm{CO}_{2}$, which is affected by the number and the size of stomata (Quick

et al. 1992). The nonstomatal factors are controlled by internal enzyme activity and photosynthetic components (Lal et al. 1996). The results of this study show that the $P_{\mathrm{N}}$, $g_{\mathrm{s}}, E$, and WUE decreased with decreasing light intensity. This is consistent with the previous study on Centrosema (DC.) Benth (Guenni et al. 2018). The $C_{\mathrm{i}}$ increased with decreasing light intensity. Previous studies showed that if the changing trend of $P_{\mathrm{N}}$ and $C_{\mathrm{i}}$ is opposite, then the main factor limiting the progress of photosynthesis must be the nonstomatal factor (Flexas and Medrano 2002). Therefore, we believe that shading treatment inhibits the photosynthesis in E. senticosus by nonstomatal limitation.

$\mathrm{Chl}$ fluorescence is related to various reaction processes in photosynthesis. The results showed that with the passing of shading treatment time, the $\mathrm{F}_{0}$ increased in the $Z_{2}$, and decreased in the $Z_{1}$ (Fig. 1A). It was shown that nonphotochemical energy dissipation reduces $F_{0}$ and 
the damage to photosynthetic machinery increases $F_{0}$ (Zhang 1999). The results of this study indicated that the PSII was damaged in $Z_{2}$ (Antal et al. 2013). This study showed that $F_{m}$ increased in the shading treatment group and was higher in $\mathrm{Z}_{1}$ (Fig. $1 B$ ). It indicated that the shading treatment promoted electron transport through PSII. The results of the above two parameters are consistent with the previous research on Aloe vera L. (Hazrati et al. 2016). The results of this study showed that the $F_{v} / F_{0}$ and $F_{v} / F_{m}$ were not different between $Z_{1}$ and $G K$. The two parameters decreased in $\mathrm{Z}_{2}$ with the shading time (Fig. $\left.1 C, D\right)$. The results indicate that $Z_{2}$ inhibited the light energy conversion efficiency of PSII (Demmig-Adams et al. 1996). In short, $\mathrm{Z}_{1}$ promotes electron transmission through PSII center, which may be one of the reasons for $Z_{1}$ promoting the growth of E. senticosus. Furthermore, $Z_{2}$ damages the PSII center, which is also the reason why the condition inhibits the growth of the plant.

Previous studies showed that syringin, isofraxidin, and eleutheroside $\mathrm{E}$ are the active compounds in the roots and stems of E. senticosus (Li et al. 2006, Xu et al. 2017). The World Health Organization used syringin and eleutheroside $\mathrm{E}$ as an indicator for the quantitative determination of the plant (World Health Organization 2002). In addition, the 'Chinese Pharmacopoeia' (2010 and 2015 edition), specified isofraxidin and syringin as a quantitative standard for $E$. senticosus, respectively (Committee C. P. 2010, 2015). The results showed that the above-mentioned three active components accumulated more in the roots and stems (Fig. $3 F-H$ ). This verified the using of the three compounds as quality control indicators of E. senticosus and coincided with the previous research results (Li et al. 2006, Cheng 2009). The result also indicated that the relative quality of $E$. senticosus roots and stems was better in $\mathrm{Z}_{1}$. Three flavonoids, including rutin, hyperoside, and kaempferol (Fig. 3C-E), accumulated in the leaves. This is consistent with previous studies on the active compounds of E. senticosus leaves (Chen et al. $2002 a, b)$. Our results also indicated that the relative quality of leaves was the best in $\mathrm{Z}_{1}$. L-phenylalanine is an essential metabolite in the metabolism of shikimic acid. It is a precursor metabolite for the synthesis of lignin, coumarin, and flavonoid compounds. In this study, the accumulation of the L-phenylalanine in various organs was different (Fig. 3A); its metabolic regulation mechanism needs further research using enzyme and transcriptomics techniques.

In this study, we found that $\mathrm{C}_{6}-\mathrm{C}_{3}-\mathrm{C}_{6}$ type phenolics, including genistein, luteolin, and quercetin, accumulated more in $Z_{2}$. This result is in accord with previous studies on the effect of light intensities on phenolics in maize. The limited light-induced anthocyanin accumulation in maize was mainly activated due to phenylalanine ammonia lyase (PAL) (Pál et al. 2020). The results of a research on ginger also show that low light intensity is conducive to the accumulation of flavonoids. Moreover, different photosynthetic rates at different light intensities may be related to the absence or presence of certain flavonoids (Ghasemzadeh et al. 2010). In addition, we also found that the accumulation of flavonoids in active medicinal ingredients is different from that of phenolics. This result is similar to the previous study on lettuce; it may be because the light intensity regulates different pathways of flavonoids production in plants (Pérez-López et al. 2018). The $\mathrm{C}_{6}-\mathrm{C}_{1}$ and $\mathrm{C}_{6}-\mathrm{C}_{3}$ type phenolics mainly accumulated in $\mathrm{Z}_{1}$. They have the antibacterial and antioxidant capacity and improve the disease resistance of E. senticosus (Dey et al. 2005, Chang et al. 2007). The result of a previous study is different from this study, which showed that the strong light could promote the synthesis of cinnamic acid in lettuce (Zhan et al. 2012). Therefore, we believe that the response mechanism of phenolics to light intensity in different species is different, and the mechanism needs to be explained by further metabolomics research. In summary, most of the phenolics with protective effects accumulated in $Z_{1}$, which may be one of the mechanisms how $\mathrm{Z}_{1}$ promotes the growth of $E$. senticosus.

Conclusions: This study investigated the changes caused by shading treatments on the morphological, photosynthetic characteristics, and secondary metabolites in E. senticosus. The growth parameters showed that $Z_{1}$ promoted the growth of the plants. $Z_{1}$ also promoted the leaf photosynthesis, while $Z_{2}$ inhibited photosynthesis. The chlorophyll fluorescence parameters indicated that $\mathrm{Z}_{2}$ inhibited the PSII activity. Most of the medicinal compounds accumulated in $Z_{1}$, which indicated that the relative quality of E. senticosus is better in $Z_{1}$. Most of the defensive phenolics accumulated in $Z_{1}$. In short, $Z_{1}$ promoted the growth and the accumulation of medicinal compounds in E. senticosus by enhancing photosynthesis and increasing the accumulation of defensive phenolics. This study may provide some experimental basis for further study about the metabolic regulation mechanism of the E. senticosus under shade stress.

\section{References}

Abidi F., Girault T., Douillet O. et al.: Blue light effects on rose photosynthesis and photomorphogenesis. - Plant Biol. 15: 67-74, 2013.

Aleric K.M., Kirkman L.K.: Growth and photosynthetic responses of the federally endangered shrub, Lindera melissifolia (Lauraceae), to varied light environments. - Am. J. Bot. 92: 682-689, 2005.

Antal T.K., Kolacheva A., Maslakov A. et al.: Study of the effect of reducing conditions on the initial chlorophyll fluorescence rise in the green microalgae Chlamydomonas reinhardtii. Photosynth. Res. 114: 143-154, 2013.

Arena M.E., Postemsky P.D., Curvetto N.R.: Changes in the phenolic compounds and antioxidant capacity of Berberis microphylla $\mathrm{G}$. Forst. berries in relation to light intensity and fertilization. - Sci. Hortic.-Amsterdam 218: 63-71, 2017.

Arouca A., Grassi-Kassisse D.M.: Eleutherococcus senticosus: studies and effects. - Health 5: 1509-1515, 2013.

Berry J.A., Downton W.J.S.: Environmental regulation of photosynthesis. - In: Govindjee (ed.): Photosynthesis: Development, Carbon Metabolism, and Plant Productivity. Pp. 263-343. Academic Press, New York 1982.

Chang Y.C., Lee F.W., Chen C.S. et al.: Structure-activity relationship of C6-C3 phenylpropanoids on xanthine oxidaseinhibiting and free radical-scavenging activities. - Free 
Radical Bio. Med. 43: 1541-1551, 2007.

Chen M., Song F., Guo M. et al.: Identification of the flavonoid constituents from leaves of Acanthopanax senticosus Harms. - Chem. J. Chin. Univ. 23: 805-808, 2002a.

Chen M.L., Song G.R., Guo M.Q. et al.: Analysis of flavonoids from leaves of Acanthopanax senticosus Harms. - Chin. J. Anal. Chem. 30: 690-694, 2002b.

Cheng K.M.: [Syringin contents analysis of Acanthopanax senticosus in different growing period]. - J. Anhui Agric. Sci. 30: 68, 2009. [In Chinese]

Committee C. P.: [Chinese Pharmacopoeia.] Edition 2010. Pp. 192-193. China Medical Science Press, Beijing 2010. [In Chinese]

Committee C. P.: [Chinese Pharmacopoeia.] Edition 2015. Pp. 206-207. China Medical Science Press, Beijing 2015. [In Chinese]

Demmig-Adams B., Adams III W.W., Barker D.H. et al.: Using chlorophyll fluorescence to assess the fraction of absorbed light allocated to thermal dissipation of excess excitation. Physiol. Plantarum 98: 253-264, 1996.

Dey G., Chakraborty M., Mitra A.: Profiling C6-C3 and C6-C1 phenolic metabolites in Cocos nucifera. - J. Plant Physiol. 162: 375-381, 2005.

Fan Y., Chen J., Wang Z. et al.: Soybean (Glycine max L. Merr.) seedlings response to shading: leaf structure, photosynthesis and proteomic analysis. - BMC Plant Biol. 19: 34, 2019.

Feijó N.S., Mielke M.S., Gomes F.P. et al:: Growth and photosynthetic responses of Gallesia integrifolia (Spreng.) Harms and Schinus terebinthifolius Raddi seedlings in dense shade. - Agroforest. Syst. 77: 49, 2009.

Flexas J., Medrano H.: Drought-inhibition of photosynthesis in $\mathrm{C}_{3}$ plants: Stomatal and non-stomatal limitations revisited. Ann. Bot.-London 89: 183-189, 2002.

Gao J., Song Z., Liu Y.: Response mechanisms of leaf nutrients of endangered plant (Acer catalpifolium) to environmental factors varied at different growth stages. - Glob. Ecol. Conserv. 17: e00521, 2019.

Ghasemzadeh A., Jaafar H.Z.E., Rahmat A.: Synthesis of phenolics and flavonoids in ginger (Zingiber officinale Roscoe) and their effects on photosynthesis rate. - Int. J. Mol. Sci. 11: 4539-4555, 2010.

Guenni O., Romero E., Guédez Y. et al.: Influence of low light intensity on growth and biomass allocation, leaf photosynthesis and canopy radiation interception and use in two forage species of Centrosema (DC.) Benth. - Grass Forage Sci. 73: 967-978, 2018.

Hammerschmidt R.: Environment, growth regulators and agerelated resistance. - Physiol. Mol. Plant P. 65: 1-2, 2004.

Hazrati S., Tahmasebi-Sarvestani Z., Modarres-Sanavy S.A.M. et al.: Effects of water stress and light intensity on chlorophyll fluorescence parameters and pigments of Aloe vera L. - Plant Physiol. Bioch. 106: 141-148, 2016.

Horváth I., Szász K.: Effect of light intensity on the metabolic pathways in photosynthesis. - Nature 207: 546-547, 1965.

Jones H.: Partitioning stomatal and non-stomatal limitations to photosynthesis. - Plant Cell Physiol. 8: 95-104, 1985.

Kasprzak K., Oniszczuk T., Wójtowicz A. et al.: Phenolic acid content and antioxidant properties of extruded corn snacks enriched with kale. - J. Anal. Method. Chem. 2018: 7830546, 2018.

Khan N.A., Ninawe A.S., Sharma J., Chakrabarti R.: Effect of light intensity on survival, growth and physiology of rohu, Labeo rohita (Cyprinidae) fry. - Int. J. Radiat. Biol. 96: 552-559, 2020.

Kim H., Seong B., Lee K. et al.: Comparison of growth characteristics and quality of Korean ginseng (Panax ginseng
CA Meyer) using different shade materials. - Planta Med. 82: P283, 2016.

Kim J.K., Kang H.M., Na J.K., Choi K.Y.: Changes in growth characteristics and functional components of Lactuca indica L. Sunhyang' baby leaf vegetable by light intensity and cultivation period. - Hortic. Sci. Technol. 37: 579-588, 2019.

Kitazaki K., Fukushima A., Nakabayashi R. et al.: Metabolic reprogramming in leaf lettuce grown under different light quality and intensity conditions using narrow-band LEDs. Sci Rep.-UK 8: 7914, 2018.

Kong D.-X., Li Y.-Q., Wang M.-L. et al.: Effects of light intensity on leaf photosynthetic characteristics, chloroplast structure, and alkaloid content of Mahonia bodinieri (Gagnep.) Laferr. Acta Physiol. Plant. 38: 120, 2016.

Lal A., Ku M., Edwards G.E.: Analysis of inhibition of photosynthesis due to water stress in the $\mathrm{C}_{3}$ species Hordeum vulgare and Vicia faba: electron transport, $\mathrm{CO}_{2}$ fixation and carboxylation capacity. - Photosynth. Res. 49: 57-69, 1996.

Lazzarini L.E.S., Bertolucci S.K.V., Pacheco F.V. et al.: Quality and intensity of light affect Lippia gracilis Schauer plant growth and volatile compounds in vitro. - Plant Cell Tiss. Org. 135: 367-379, 2018.

Lee Y.T., Chiu C.S.: Grey anti-inflammation analysis of phenolic acid phenethyl esters in human neutrophils. - Int. J. Data Min. Bioinform. 11: 244-256, 2015.

Li Q., Jia Y., Xu L. et al.: Simultaneous determination of protocatechuic acid, syringin, chlorogenic acid, caffeic acid, liriodendrin and isofraxidin in Acanthopanax senticosus Harms by HPLC-DAD. - Biol. Pharm. Bull. 29: 532-534, 2006.

Oliveira G.C., Vieira W.L., Bertolli S.C., Pacheco A.C.: Photosynthetic behavior, growth and essential oil production of Melissa officinalis L. cultivated under colored shade nets. Chil. J. Agr. Res. 76: 123-128, 2016.

Pál M., Janda T., Majláth I., Szalai G.: Involvement of salicylic acid and other phenolic compounds in light-dependent cold acclimation in maize. - Int. J. Mol. Sci. 21: 1942, 2020.

Pan J., Guo B.: Effects of light intensity on the growth, photosynthetic characteristics, and flavonoid content of Epimedium pseudowushanense BL Guo. - Molecules 21: 1475, 2016.

Park S.H., Lee S.G., Kang S.K., Chung S.H.: Acanthopanax senticosus reverses fatty liver disease and hyperglycemia in ob/ob mice. - Arch. Pharm. Res. 29: 768-776, 2006.

Pérez-López U., Sgherri C., Miranda-Apodaca J. et al.: Concentration of phenolic compounds is increased in lettuce grown under high light intensity and elevated $\mathrm{CO}_{2}$. - Plant Physiol. Bioch. 123: 233-241, 2018.

Poolman M.G., Kundu S., Shaw R., Fell D.A.: Responses to light intensity in a genome-scale model of rice metabolism. - Plant Physiol. 162: 1060-1072, 2013.

Quick W., Chaves M., Wendler R. et al.: The effect of water stress on photosynthetic carbon metabolism in four species grown under field conditions. - Plant Cell Environ. 15: 25-35, 1992.

Tafoya F.A., Juárez M.G.Y., Orona C.A.L. et al.: Sunlight transmitted by colored shade nets on photosynthesis and yield of cucumber. - Ciênc. Rural 48: e20170829, 2018.

Tang W., Hazebroek J., Zhong C. et al.: Effect of genetics, environment, and phenotype on the metabolome of maize hybrids using GC/MS and LC/MS. - J. Agr. Food Chem. 65: 5215-5225, 2017.

Tugizimana F., Djami-Tchatchou A.T., Steenkamp P.A. et al.: Metabolomic analysis of defense-related reprogramming in Sorghum bicolor in response to Colletotrichum sublineolum infection reveals a functional metabolic web of phenylpropanoid and flavonoid pathways. - Front. Plant Sci. 9: 1840, 
2019.

Wang C., Gao H., Cai E. et al.: Protective effects of Acanthopanax senticosus - Ligustrum lucidum combination on bone marrow suppression induced by chemotherapy in mice. - Biomed. Pharmacother. 109: 2062-2069, 2019.

Wang C.L., Guo Q.S., Zhu Z.B., Cheng B.X.: Physiological characteristics, dry matter, and active component accumulation patterns of Changium smyrnioides in response to a light intensity gradient. - Pharm. Biol. 55: 581-589, 2017.

Warren R.L., Keeling C.I., Yuen M.M. et al.: Improved white spruce (Picea glauca) genome assemblies and annotation of large gene families of conifer terpenoid and phenolic defense metabolism. - Plant J. 83: 189-212, 2015.

World Health Organization: World Health Organization Monographs on Selected Medicinal Plants. Vol. 2. Pp. 285-299. World Health Organization, Geneva 2002.

Xu M., Wang Y., Wang Q. et al.: Changes in growth and photosynthetic parameters and medicinal compounds in Eleutherococcus senticosus Harms under drought stress. HortScience 54: 2202-2208, 2019.

Xu M., Wang Y., Wang Q. et al:: Targeted developmentdependent metabolomics profiling of bioactive compounds in Acanthopanax senticosus by UPLC-ESI-MS. - Nat. Prod. Commun. 15: 1934578X20910553, 2020.

$\mathrm{Xu}$ S., Cui B., Zhao G. et al.: Simultaneous determination of eleutheroside $\mathrm{E}$, isothiazine, chlorogenic acid, protocatechuic acid and oleanolic acid in Acanthopanax by LC-MS/MS. Bot. Res. 6: 201-210, 2017.

Yang C.-Q., Iqbal N., Hu B.-Y. et al.: Targeted metabolomics analysis of fatty acids in soybean seeds using GC-MS to reveal the metabolic manipulation of shading in the intercropping system. - Anal. Methods 9: 2144-2152, 2017.

Yang M., Liu M., Lu J., Yang H.: Effects of shading on the growth and leaf photosynthetic characteristics of three forages in an apple orchard on the Loess Plateau of eastern Gansu, China. - PeerJ 7: e7594, 2019.

Yi J.M., Kim M.S., Seo S.W. et al.: Acanthopanax senticosus root inhibits mast cell-dependent anaphylaxis. - Clin. Chim. Acta 312: 163-168, 2001.

Yoon T.J., Yoo Y.C., Lee S.W. et al.: Anti-metastatic activity of Acanthopanax senticosus extract and its possible immunological mechanism of action. - J. Ethnopharmacol. 93: 247253, 2004

Zhan L., Li Y., Hu J., Fan H.: Browning inhibition and quality preservation of fresh-cut romaine lettuce exposed to high intensity light. - Innov. Food Sci. Emerg. Technol. 14: 70-76, 2012.

Zhang S.: [A discussion on chlorophyll fluorescence kinetics parameters and their significance]. - Chin. Bull. Bot. 16: 444448, 1999. [In Chinese].

Zhou A.Y., Song B.W., Fu C.Y. et al.: Acanthopanax senticosus reduces brain injury in mice exposed to low linear energy transfer radiation. - Biomed. Pharmacother. 99: 781-790, 2018a.

Zhou J., Li P., Wang J., Fu W.: Growth, photosynthesis, and nutrient uptake at different light intensities and temperatures in lettuce. - HortScience 54: 1925-1933, 2019.

Zhou Y., Cheng C., Baranenko D. et al.: Effects of Acanthopanax senticosus on brain injury induced by simulated spatial radiation in mouse model based on pharmacokinetics and comparative proteomics. - Int. J. Mol. Sci. 19: 159, 2018 b.

Zhu Z.B., Yang J.F., Guo Q.S. et al.: [Effects of light intensity on growth, quality and antioxidant activities of Sedum sarmentosum.] - Chin. J. Chin. Mater Med. 43: 4404-4409, 2018. [In Chinese]

(C) The authors. This is an open access article distributed under the terms of the Creative Commons BY-NC-ND Licence. 